\title{
The effectiveness of attentional bias modification on attentional bias, pre- attentional bias and craving in abstinent addicts
}

\author{
Ali Nowrouzi ${ }^{1}$, Najmeh Hamid ${ }^{2 *}$ (ID, Kumars Beshlideh $^{3}$, Seyed Ali Marashy ${ }^{4}$ \\ 1. PhD Student in Psychology, Department of Clinical Psychology, College of Education and Psychology, Shahid Chamran University of Ahvaz, \\ Ahvaz, Iran \\ 2. Associate Professor of Clinical Psychology, Department of Clinical Psychology, College of Education and Psychology, Shahid Chamran University \\ of Ahvaz, Ahvaz, Iran \\ 3. Professor of Psychology, Department of Psychology, College of Education and Psychology, Shahid Chamran University of Ahvaz, Ahvaz, Iran \\ 4. Assistant Professor of Clinical Psychology, Department of Clinical Psychology, College of Education and Psychology, Shahid Chamran University \\ of Ahvaz, Ahvaz, Iran
}

Recieved: 1 Jan. 2019

Revised: 29 Sep. 2019

Accepted: 13 Jan. 2020

\section{Keywords}

Attentional bias modification

Reinforcement and Punishment

Dot-Probe task

Pre-attentional bias

Craving

Corresponding author

Najmeh Hamid, Department of Clinical Psychology, College of Education and Psychology, Shahid Chamran University of Ahvaz, Ahvaz, Iran

Email: N.hamid@scu.ac.ir

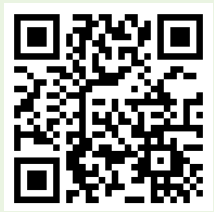

doi.org/10.30699/icss.21.4.12

\section{Abstract}

Introduction: For many years, it has been emphasized on the role of attentional bias in addiction-related disorders, including its role in craving and relapse. This reseasrch aimed to investigate, the effectiveness of attentional bias modification on attention bias, pre-attentional bias and craving in abstinent addicts.

Methods: Three groups (control, attentional bias modification and attentional bias modification with reinforcement and punishment) in three phases (pre-test, post-test, and follow up) assessed in attentional bias, pre-attentional bias, and craving. During the pretest and post-test, the control group received placebo training, while the second group received attentional bias modification training, and the third group received attentional bias modification training with reinforcement and punishment, respectively. To measure attentional bias, pre-attentional bias, and interventions, and to measure craving Dotprobe task test and Brief Substance Craving Scale were used respectively.

Results: The results indicated that there was a significant difference between three groups in attentional bias in post-test and follow-up, the pre-attentional bias in post-test, and craving in the post-test. The control group obtained a higher score in pre-attentional bias than two experimental groups in the pre-attentional bias in follow up and attentional bias modification with reinforcement and punishment group obtained a lower score in craving than two other groups in craving in follow up.

Conclusion: It seems that adding reinforcement and punishment to the classical intervention of attentional bias modification can lead to improving the effectiveness of this intervention. Besides, interventions based on attention bias modification are efficient interventions. 


\title{
اثربخشى اصلاح سوكيرى توجه بر سو تيرى توجه، سوكيرى يشى توجه و وسوسه در معتادان در حال ترك
}

\author{
على نوروزى'، نجمه حميد " (D) ، كيومرث بشليده"، سيد على مرعشى'

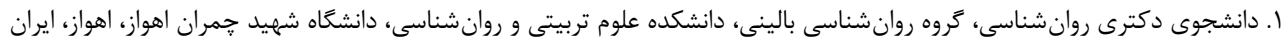

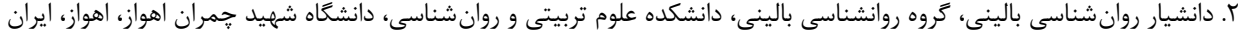

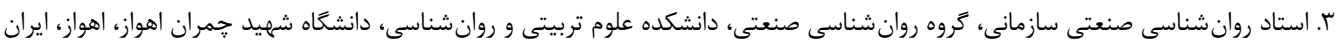

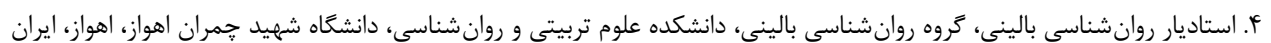

\section{هاs}

مقلدمه: سالهاست كه بر نقش سوكيرى توجه در اختلالات مرتبط با اعتياد از جمله نقش آن در وسوسه و لغزش تأكيد مىشود. در يزوهش حاضر به بررسى اثربخشى اصلاح سوكيرى توجه بر سوگيرى توجه، سوگيرى بيشتوجه و وسوسه در معتادان در حال ترك يرداخته شد. روش كار: سه كروه (اصلاح سوكيرى توجه، اصلاح سوكيرى توجه به همراه تقويت و تنبيه و كنترل) در سه مرحله

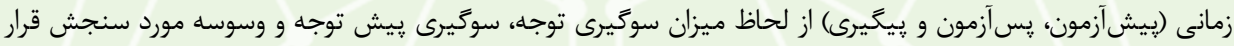
كرفتند. بين يِيشآزمون و پِآزمون گَروه كنترل مداخلهاى خنثى دريافت كرد، در حالى كه گروه اصلاح سوكيرى توجه با روش اصلاح سوكيرى متداول مورد مداخله قرار گرفت و گروه ديگر از طريق اصلاح سوكيرى توجه با تقويت و تنبيه مورد دست كارى قرار گرفت. براى سنجش سوكيرى توجه، سوكيرى پِيش توجه و همجنين مداخلات صورت گرفته از آزمون دات يروب و براى سنجش وسوسه از مقياس كوتاه وسوسه مواد استفاده گرديد. يافته ها: يافتهها حاكى از آن بود كه هر سه كروه در متغيرهاى سوكيرى توجه در پِّآزمون و پِيخيرى، سوكيرى بِيش توجه در يسآزمون و وسوسه در يسآزمون با يكديكر تفاوت معنادارى داشتند. در متغير سوكيرى پيش توجه در مرحله پِيخيرى گروه كنترل نمرات سوكيرى پيش توجه بالاترى از هر دو گروه ديگر كسب نمود. همجنين در متغير وسوسه در مرحله بِيخيرى گروه اصلاح سوكيرى به همراه تقويت و تنبيه از هر دو گروه ديخر نمرات وسوسه كمترى را كسب نمود. نتيجه كَيرى: به نظر مىرسد افزودن تقويت و تنبيه به مداخله كلاسيك اصلاح سوكيرى توجه مىتواند به بهبود اثربخشى اين مداخله بينجامد. همجنين مداخلات مبتنى بر اصلاح سوكيرى توجه، مداخلهاى كارآمد هستند.

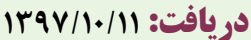

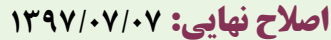

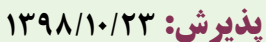

وازههاى كليلدى

اصلاح سوخيرى توجه

تقويت و تنبيه

آزمون دات بروب

سو

وسوسه

نويسنله مسئول

نجمه حميد، كروه روانشناسى بالينى،

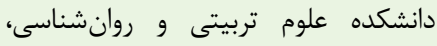
دانشعاه شهيد حمران اهواز، اهواز، ايران

ايميل: N.hamid@scu.ac.ir

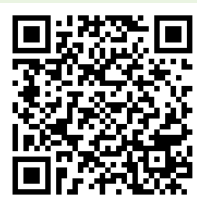

dol doi.org/10.30699/icss.21.4.12

مقلdمه

با وجود اين كه اعتياد همجنان يكى از بزركترين مشكلات دامنكير عملكردهاى شناختى مختلفى همجون يادكيرى، حافظه، توجه، استدلال

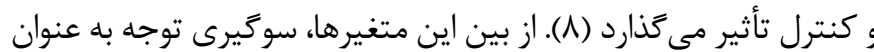

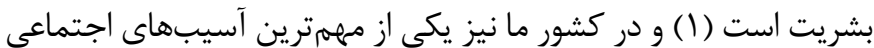
يك عامل كليدى شناخته شده است. سوگيرى توجه را مىتوان به عنوان تغيير در تمركز توجه به يك محرك خاص جه به صورت آكاهانه يا نآكآهانه تعريف كرد (9). محرك هايى كه داراى بار هيجانى هستند مى توانند موجب

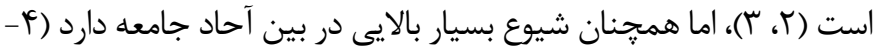
V V). در حال حاضر، بسيارى از مطالعات حيطه اعتياد بر اهميت فر آيندهاى

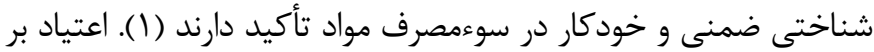


افزودن تقويت و تنبيه به مداخله اصلاح سوگيرى توجه مىتواند تأثير اين

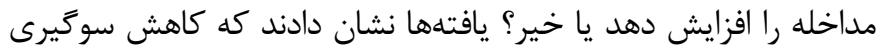
توجه در كروهى كه علاوه بر اصلاح سوكيرى از تقويت و تنبيه نيز برخوردار

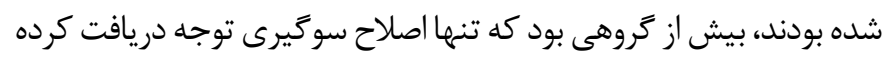

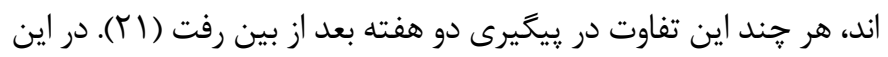

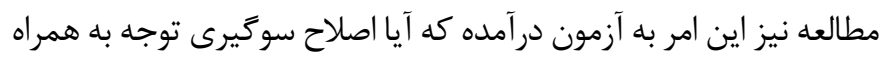

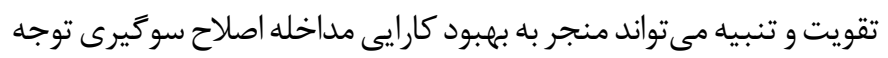
در معتادين در حال ترك شود يا خير؟ تونج همجنين اثربخشى مداخلات اصلاح سوگيرى توجه بر بيش توجه به جز در يك يروهش (rT) كه بر روى مصرفكنندكان سيكار بوده است تاكنون بررسى نشده است. از آنجا كه سوكيرى ييش توجه نقش مهمى در شدت اختلال و لغزش ايفا مى كند (ها)، مطالعه حاضر به بررسى تغييرات در سوكيرى ييش توجه با استفاده از مداخلات اصلاح سوكيرى توجه يرداخته

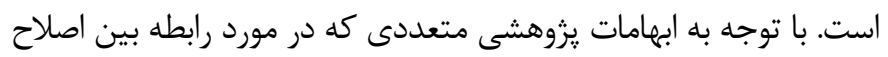

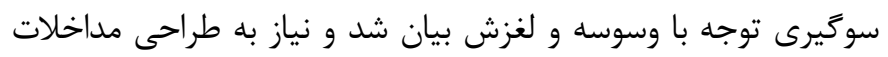

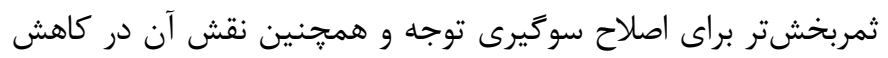

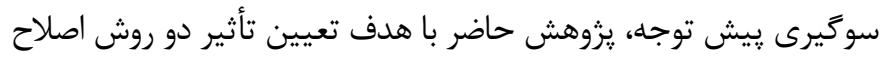

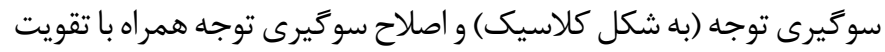
و تنبيه در كاهش سوكيرى توجه، سوكيرى ييش توجه و وسوسه انجام شد.

\section{روش كار}

با توجه به فرضيات مطرح شده در يزوهش حاضر از طرح آزمايشى با گروه

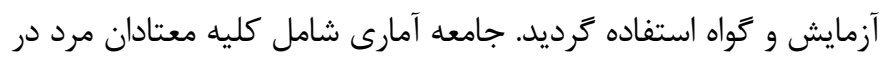

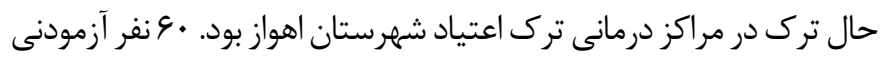

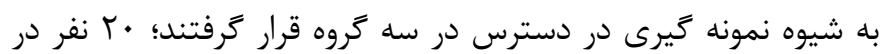

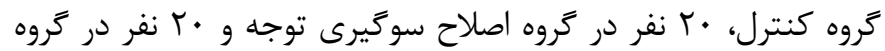
اصلاح سوكيرى توجه به همراه تقويت و تنبيه. دليل انتخاب .4 نفر اين بود كه بايد در هر گروه آزمايشى حداقل ها نفر حضور مى داشتند (TV). شركت كنند

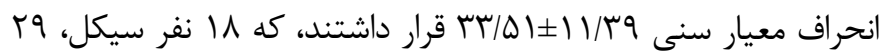

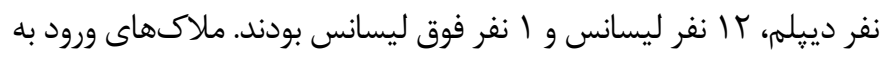

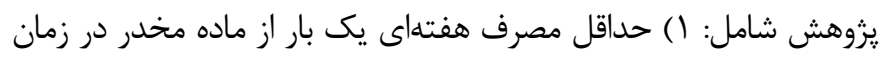

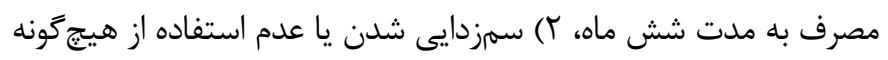

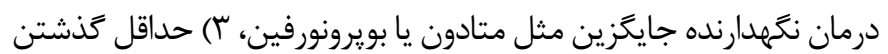
دو هفته از آغاز دوره ياكى بدون داشتن لغزش و \&) عدم ابتلا به اختلالات سايكوتيك يا ساير اختلالات بالينى مخل فرآيند يزوهش بود. ملاكهاى

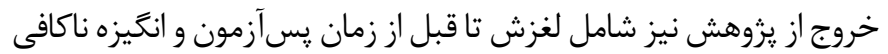

سوگيرى توجه در فرد شوند؛ كه اين محركها در افراد وابسته به مواد، محركهاى مرتبط با مواد است (•(1). مطالعات متعددى تاكنون، وجود

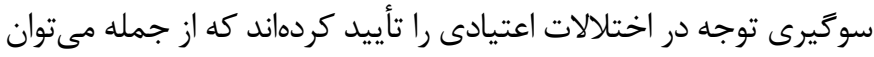

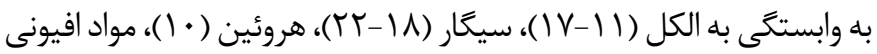

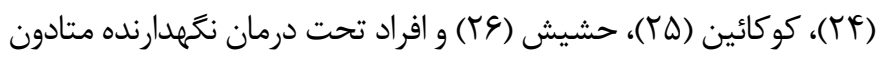
Pre-) اشاره كرد. يزوهشها علاوه بر توجه، به مطالعه يِيش توجن (1) (TV) YAttentional Bias

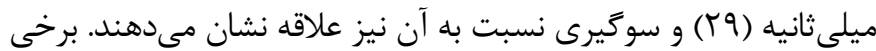
مطالعات حاكى از آن است كه افرادى كه تصميم به ترك اعتياد خود دارند، هنخامى كه محرك آنقدر طولانى ارائه شود كه فرد بتواند هشيارانه

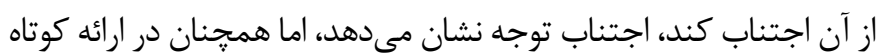
مدت محرك (بيش توجه) كه كنترل ارادى بر سيستم توجهى خونى خود ندارد

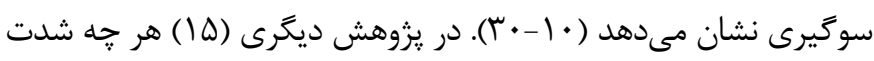

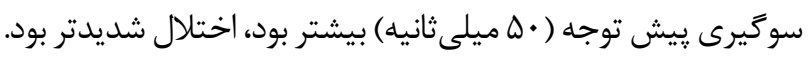

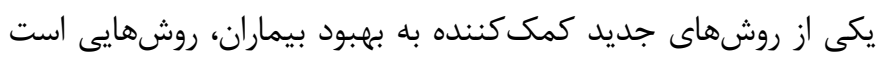

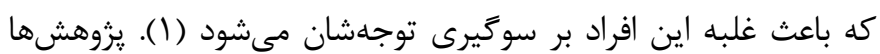
نشان مىدهند كه آموزش سوءمصرف كنند كان مواد براى غلبه بر سوگيرى توجهشان مىتواند سوكيرى توجه آنها را نسبت به ماده مصرفى كم كند

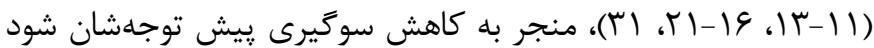

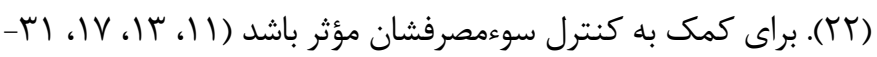

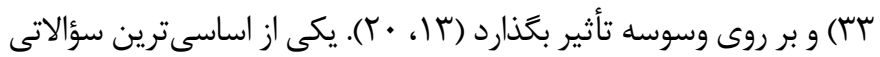

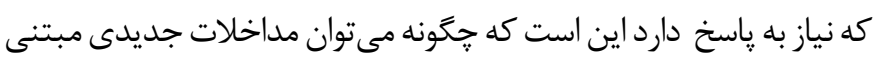
بر اصلاح سوكيرى توجه را طراحى نمود كه تأثير بيشترى بر رفتارهاى

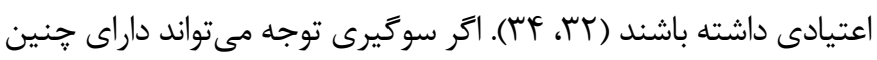
نقش تعيين كنندهاى در اختلالات اعتيادى باشد، لزوم بهبود مداخلات اصلاح سوكيرى توجه بهشدت احساس مىشود. Anderson و همكاران در مقاله خود توضيح مىدهند كه مغز انسان همواره به دنبال ادراك محركهايى است كه علامت بالقوهاى از به دست آوردن ياداش هستند

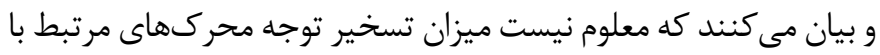
اعتياد تا جه حد با تداعىهاى بين محرك و ياداش (آزادسازى دويامين)

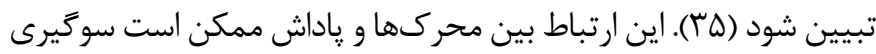

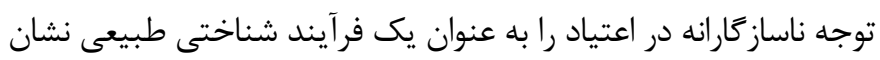

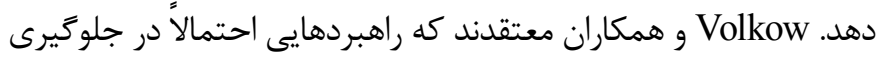

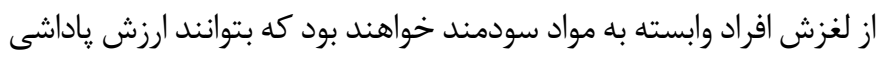
نشانههاى مرتبط با مواد را كاهش و ارزش ياداشى نشانههاى غير مرتبط با ليا مواد را افزايش دهند و اثر شرطى محر كهاى شرطى شده را خنثى نمايند (צץ). در همين راستا، نوروزى و تقوى به بررسى اين امر يرداختند كه آيا 
استفاده شد. ضمناً زمان ارائه تشويق و تنبيه ا ثانيه بود و بلافاصله يس از

$$
\text { همان كوشش ارائه مىشد. }
$$

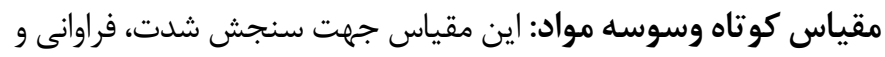

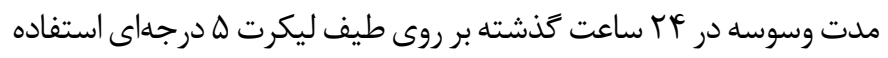
شد. اين مقياس براى وسوسه هر ماده (جه جزء مواد اعتيادى شركت كن كنينده

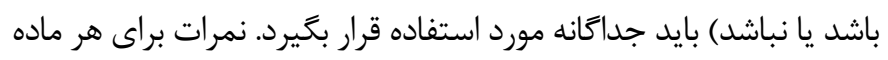

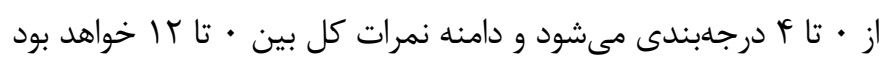

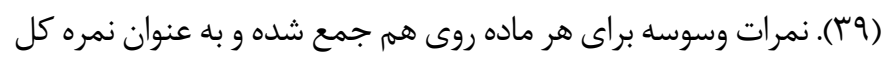

وسوسه استفاده شد.

روند اجراى يزوهش: تمام مراحل سنجش و مداخله در مكانى آرام در

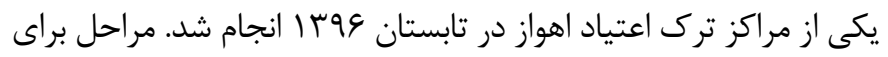

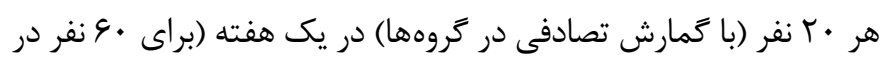

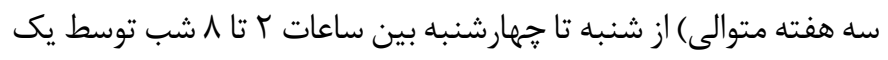

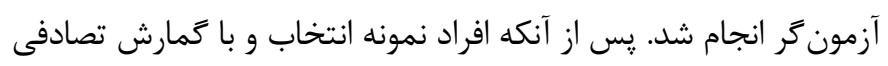

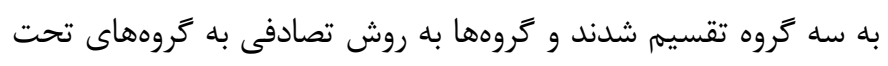

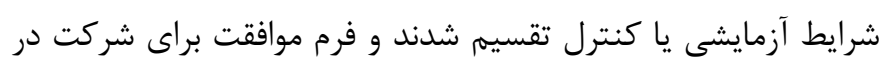

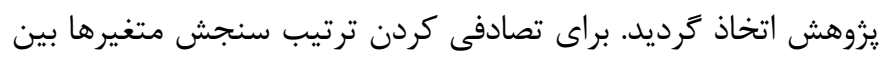

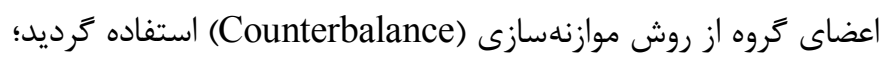

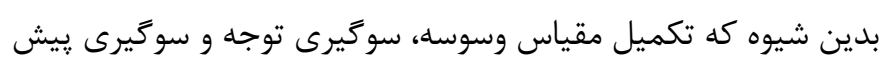

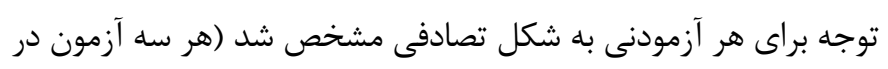

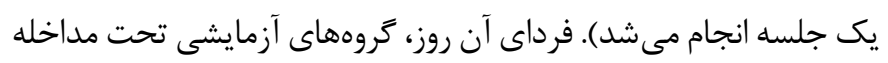

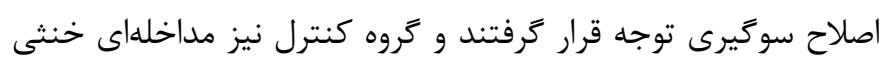

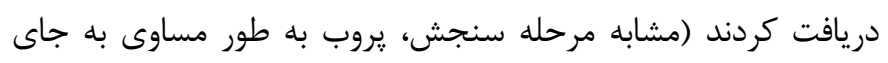

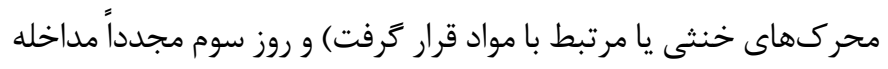

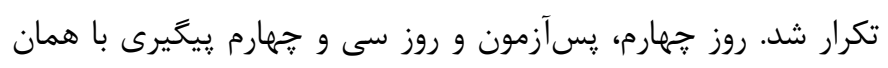

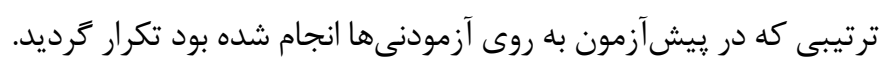

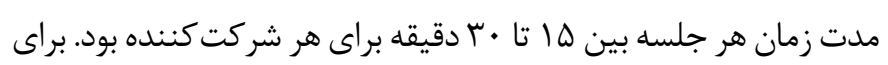

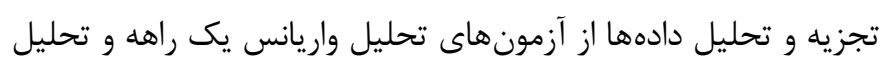

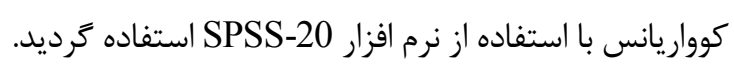

يافته ها

ييش از تجزيه و تحليل دادهها جهت بررسى فرضيه يزوهش، با استفاده

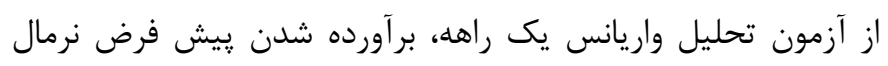

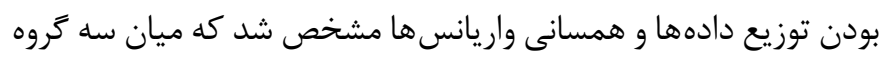

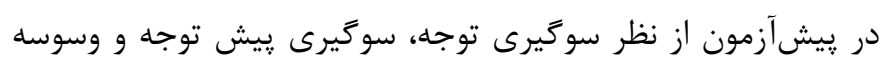

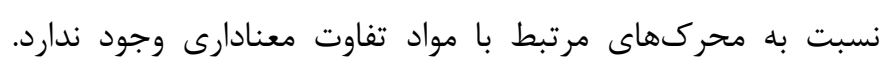

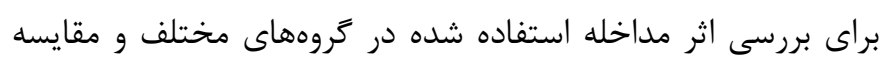

جهت دركيرى فعالانه در يزوهش بود. براى سنجش سوكيرى توجه،

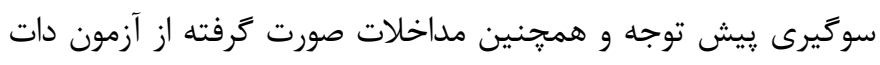
يروب و براى سنجش وسوسه از مقياس كوتاه وسوسه مواد استفاده كرديد.

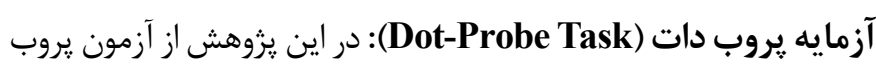
دات هم براى سنجش سوكيرى توجه و هم براى اصلاح آن مورد استفاده

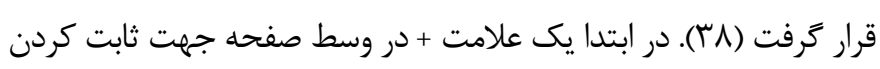

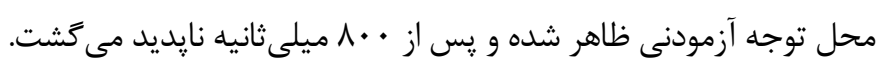

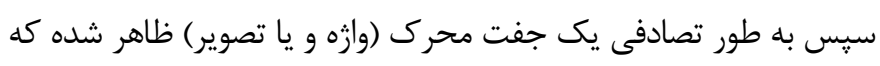

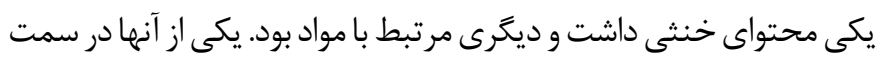

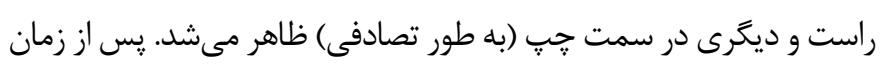

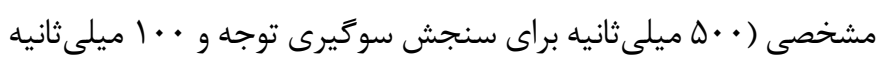

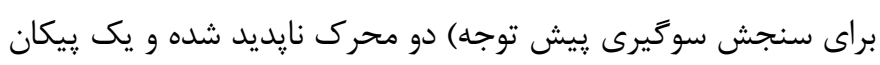

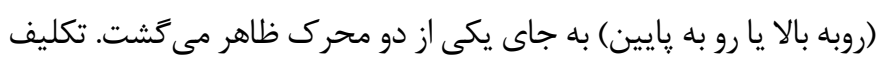

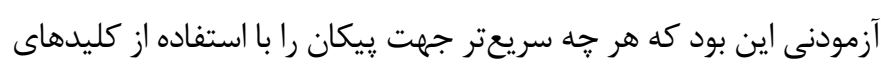

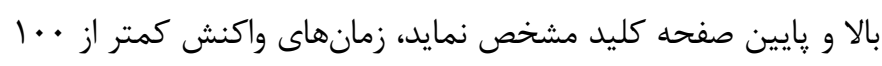

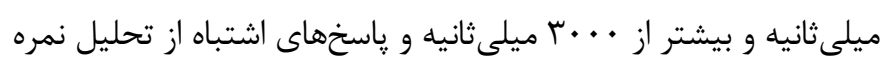

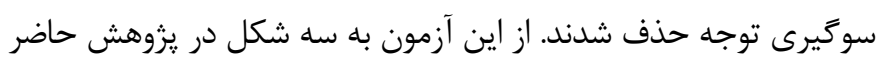

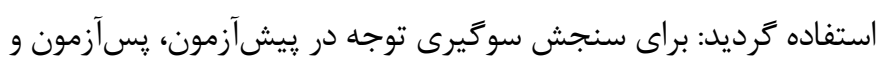

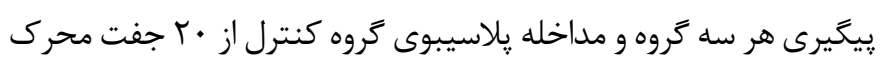

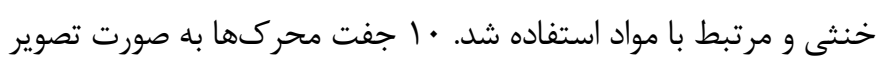

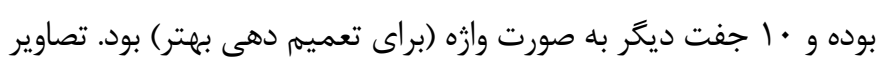

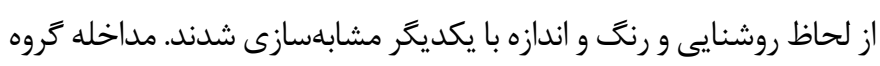
اصلاح سوكيرى توجه به همراه تقويت و تنبيه نيز مشابه مداخله كروه

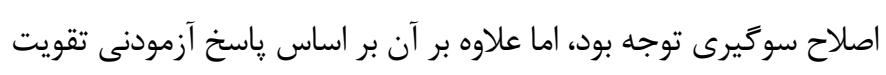

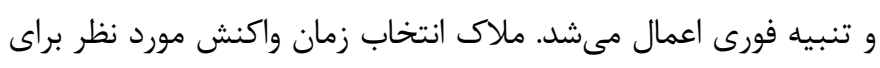

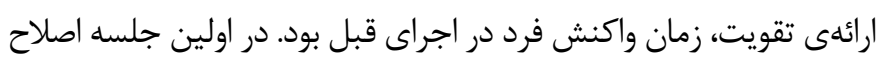

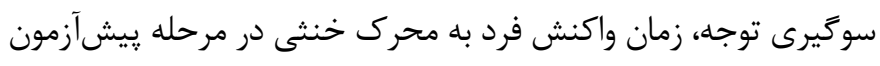

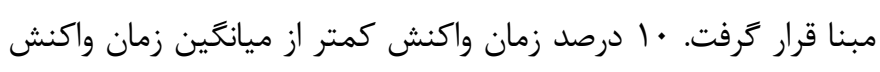

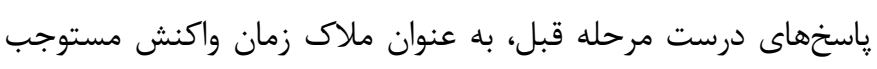

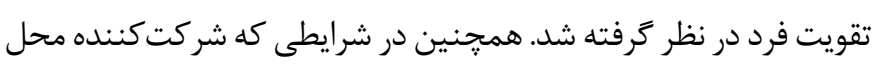

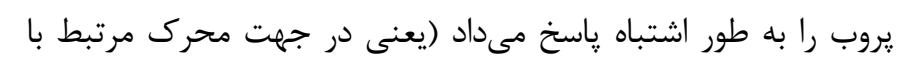

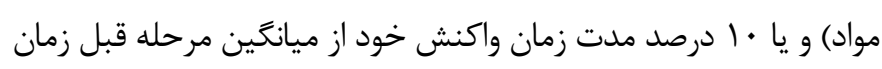

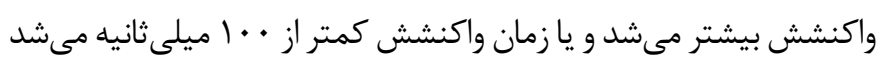

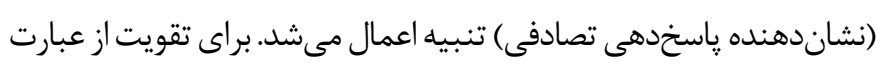

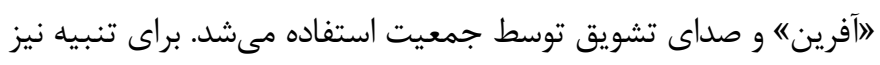

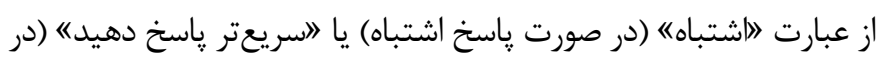

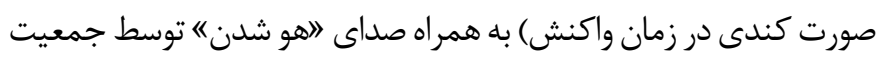


آنها، يس از بررسى و برآورده شدن تمام يِشفرضها، از شش آزمون ِيشفرضهاى لازم براى انجام تحليل كوواريانس برقرار بود. جدول 1

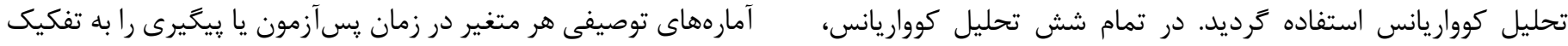

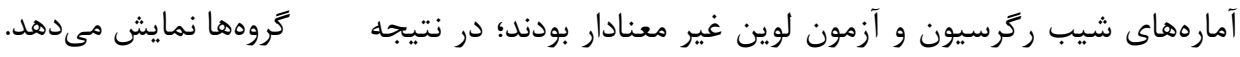
جدول ا. آمارههاى توصيفى نمرات سوگيرى توجه، پِيش توجه و وسوسه در يِآزمون و بيخيرى به تفكيك سه گروه

\begin{tabular}{|c|c|c|c|}
\hline فراوانى & ميانگين土|نحر اف استاندارد & تروه & متغير \\
\hline$r \cdot$ & $|Q / 9 \cdot \pm r| / \mid$ & 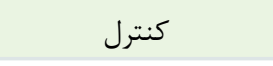 & \multirow{3}{*}{ سوكيرى توجه در رِيش آزمون } \\
\hline$r \cdot$ & $|F / \Lambda \Delta \pm r r /| \varepsilon$ & اصلاح سوكيرى توجه & \\
\hline$r \cdot$ & $|\varepsilon / \cdot \Delta \pm r| / r \Delta$ & اصلاح به همراه تقويت & \\
\hline$r \cdot$ & $r T / \Lambda \cdot \pm 1 \Lambda / 9 \Delta$ & 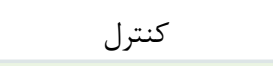 & \multirow{3}{*}{ سوكيرى توجه در يس آزمون } \\
\hline$r \cdot$ & $-r / \cdot \Delta \pm 19 / V 9$ & اصلاح سو & \\
\hline$r \cdot$ & $-r T / V \Delta \pm \mid N / \Delta$ & اصلاح به همراه تقويت & \\
\hline$r \cdot$ & $r \mid / \Lambda \cdot \pm 19 / V \Delta$ & 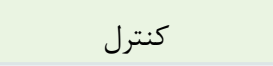 & \multirow{3}{*}{ سوكيرى توجه در ييگيرى } \\
\hline$r \cdot$ & $G|V \Delta \pm| N / T \mid$ & اصلاح سوكيرى توجه & \\
\hline$r \cdot$ & $-11 / v \cdot \pm 14 / 9 \Delta$ & اصلاح به همراه تقويت & \\
\hline$r \cdot$ & $1 V / 9 \cdot \pm 19 / 94$ & كنترل & \multirow{3}{*}{ سوَيرى يِيش توجه در } \\
\hline$r \cdot$ & $|9| \cdot \Delta \pm r \mid / r \Delta$ & اصلاح سوكيرى توجه & \\
\hline$r \cdot$ & $r F / V \Delta \pm 19 / \Delta \Delta$ & اصلاح به همراه تقويت & \\
\hline$r \cdot$ & $r r / \cdots \pm 1 \Lambda / r q$ & كنترل & \multirow{3}{*}{ سو سيرى يِيش توجه در } \\
\hline$r \cdot$ & $\cdot / 90 \pm 19 / \cdot 9$ & اصلاح سوگيرى توجه & \\
\hline$r \cdot$ & $-|r / \cdot \cdot \pm| \varepsilon / \Delta F$ & اصلاح به همراه تقويت & \\
\hline$r \cdot$ & $|\varepsilon / 4 \cdot \pm| \varepsilon / T \mid$ & كنترل & \multirow{3}{*}{ سو يرى پيش توجه در پييخيرى } \\
\hline$r \cdot$ & $1 / / \Delta \pm 1 \Delta / 9 \Delta$ & اصلاح سوكيرى توجه & \\
\hline$r \cdot$ & $-\uparrow / \varepsilon \Delta \pm \mid \Lambda / V \psi$ & اصلاح به همراه تقويت & \\
\hline$r \cdot$ & $1 Q / 9 \cdot \pm \Delta / V T$ & كنترل & \multirow{3}{*}{ وسوسه در يِيش آزمون } \\
\hline$r \cdot$ & $|r / r \cdot \pm \psi / q|$ & اصلاح سوكيرى توجه & \\
\hline$r \cdot$ & $|\varepsilon / F \cdot \pm \Delta /| V$ & اصلاح به همراه تقويت & \\
\hline$r \cdot$ & $|r /| \cdot \pm F / F V$ & كنترل & \multirow{3}{*}{ وسوسه در يس آزمون } \\
\hline$r \cdot$ & $1 \cdot / 1 \Delta \pm r / \cdot \Lambda$ & اصلاح سوكيرى توجه & \\
\hline$r \cdot$ & $\varepsilon \mid \Lambda \cdot \pm r / \cdot \cdot 1$ & اصلاح به همراه تقويت & \\
\hline$r \cdot$ & $\mid Q / r \cdot \pm r / q r$ & 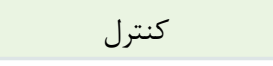 & \multirow{3}{*}{ وسوسه در يِيخيرى } \\
\hline$r \cdot$ & $\mid r / \Lambda \cdot \pm r / / V$ & اصلاح سوكيرى توجه & \\
\hline$r \cdot$ & $V / F \Delta \pm r / I r$ & اصلاح به همراه تقويت & \\
\hline
\end{tabular}




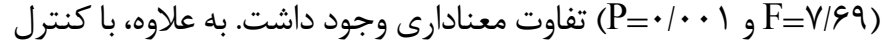
نمرات پِيش آزمون شركت كنندكان در وسوسه، بين كروهها در نمرات

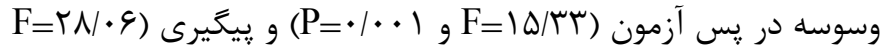

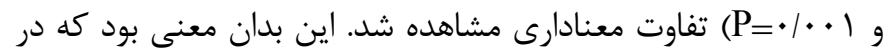

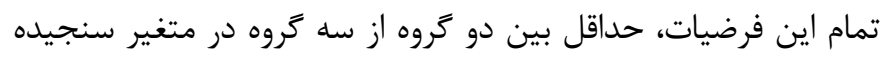

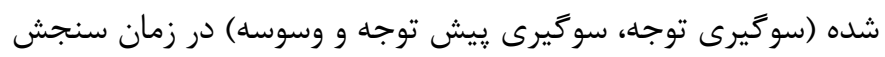
آن (يس آزمون و يیيخيرى) تفاوت معنادارى وجود داشت.
جدول ك، اثرات بين گروهى را به طور مجزا براى هر فرضيه نشان مىدهد. همانطور كه در جدول r مشاهده مى گردد با كنترل نمرات يِيش آزمون شركت كنندكان در سوكيرى توجه، بين كروهها در نمرات سوكيرى

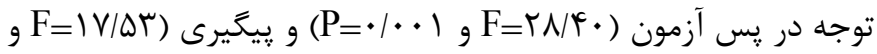

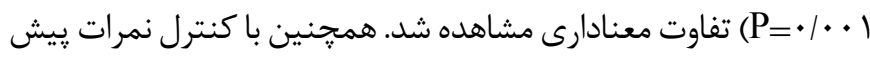
آزمون شركت كنند كان در سوكيرى ييش توجه، بين گروهها در نمرات

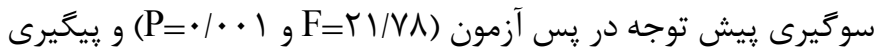

جدول ז. آزمون اثرات بين كروهى براى سه متغير سوكَيرى توجه، پِيش توجه و وسوسه در مرحله بِ آزمون و پِيكيرى

\begin{tabular}{|c|c|c|c|c|c|c|c|}
\hline ضريب اتا & $\mathbf{P}$ & $\mathbf{F}$ & مجانگَين & آزادى & مجذموع مجمرات & منبع & متغير \\
\hline$\cdot 1 \cdot \cdot 1$ & .194 & $\cdot 1 \cdot 99$ & 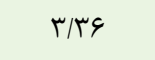 & 1 & 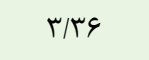 & يِيشآزمون سوكيرى توجه & \multirow{3}{*}{ سو سيرى توجه در } \\
\hline \multirow[t]{2}{*}{$\cdot 10$} & $\cdot 1 \cdot \cdot 1$ & $r \Lambda / K$. & $1 \cdot$ FrN/Fq & r & $r \cdot \wedge \Delta 9 / 9 \Lambda$ & 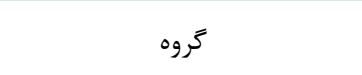 & \\
\hline & & & $r \varepsilon V / \cdot \Lambda$ & $\Delta \varphi$ & $r \cdot \Delta \Delta Q / \Delta r$ & خطا & \\
\hline$\cdot 1 \cdot \cdot 1$ & $\cdot / \vee 9$ & $\cdot 1 \cdot v$ & Tr/DT & 1 & Tr/DT & ييشآزمون سوكيرى توجه & \multirow{3}{*}{ سو سيرى توجيرى در } \\
\hline \multirow[t]{2}{*}{$\cdot / \mu$} & $\cdot 1 \cdot \cdot 1$ & IV/Dr & $\Delta S / 9 / \wedge F$ & r & $11 r r 9 / 9 \wedge$ & 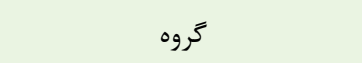 & \\
\hline & & & $M t / F T$ & $\Delta \varphi$ & IVIFF/GT & 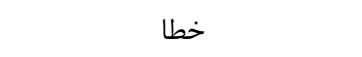 & \\
\hline$\cdot / \cdot v$ & $\cdot / \cdot r$ & $r / \& V$ & IFTV/qF & 1 & IFTV/qF & پيشىآزمون سوكيرى پِيش توجه & \multirow{3}{*}{ سو ديرى يِيش توجه } \\
\hline \multirow[t]{2}{*}{. kT } & $\cdot 1 \cdot \cdot 1$ & rI/VA & $99 \Delta T / F)$ & r & Irr.r/Ar & 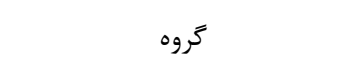 & \\
\hline & & & $r \cdot \Delta / r V$ & $\Delta \varphi$ & $|V| \cdot \mid / \cdot 1$ & خطا & \\
\hline$\cdot 1 \cdot 1$ & $\cdot / 4$ & $\cdot / v \cdot$ & $r \cdot 9 / \cdot 9$ & 1 & $r \cdot 9 / \cdot 9$ & پيشآزمون سوگيرى پيش توجه & \multirow{3}{*}{ سو ديرى پِيش توجه } \\
\hline \multirow[t]{2}{*}{$\cdot|r|$} & $\cdot 1 \cdot \cdot 1$ & $V / 99$ & TYYI/TD & r & FYAT/VI & 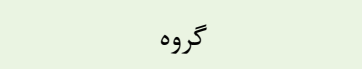 & \\
\hline & & & $r q 1 / 1 r$ & $\Delta \varphi$ & $|\varepsilon r \cdot r / \Lambda|$ & 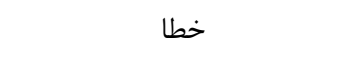 & \\
\hline$\cdot \cdot r$ & $.19 \mathrm{~V}$ &.$/ 1 \mathrm{~V}$ & $T / T V$ & 1 & $T / T V$ & ييش آزمون وسوسه & \multirow{3}{*}{ وسوسه در يس آزمون } \\
\hline \multirow[t]{2}{*}{$\cdot / \pi \Delta$} & $\cdot 1 \cdot \cdot 1$ & س & $199 / \mathrm{r}$ & r & ५११/४ब & 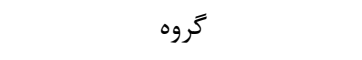 & \\
\hline & & & $\mid r / \cdot r$ & $\Delta \varphi$ & $V T q / r V$ & خطا & \\
\hline$\cdot / \cdot r$ & $\cdot / N T$ &.$/ 1 T$ & $1 / \pi 4$ & 1 & $1 / \pi 9$ & 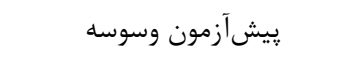 & \multirow{3}{*}{ وسوسه در ييحيرى } \\
\hline \multirow[t]{2}{*}{$\cdot 10$} &.$/ \cdot \cdot 1$ & $r N \cdot G$ & MIF/VE & r & GT /DT & 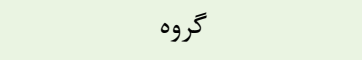 & \\
\hline & & & $\mid 1 / T 1$ & $\Delta \varphi$ & GYV/QA & خطا & \\
\hline
\end{tabular}

مده است. بر اساس جدول r مشاهده مىشود كه بين هر سه كروه در

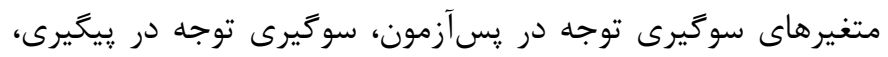

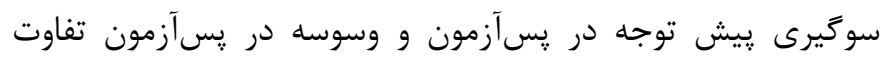

براى فهم اين كه براى هركدام از فرضيات، بين كدام گروهها در متغير

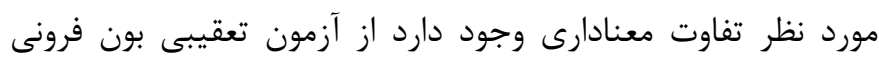

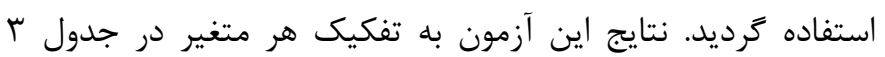


كروه اصلاح سوگيرى توجه با گروه اصلاح سوگيرى به همراه تقويت و تنبيه معنادار نبود. همجنين در متغير وسوسه در مرحله پِيكيرى كروه

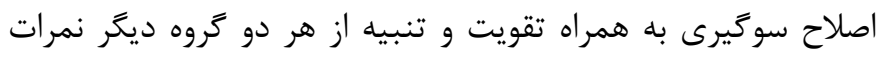

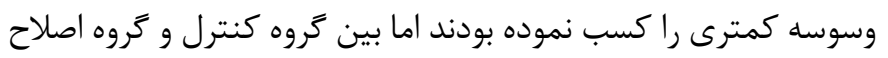
سوكيرى توجه تفاوت معنادارى مشاهده نشد.
معنادارى وجود داشت، به طورى كه گروه كنترل از هر دو گروه و

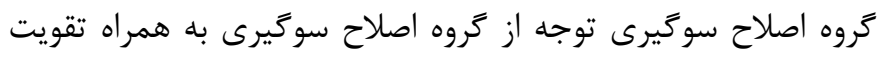

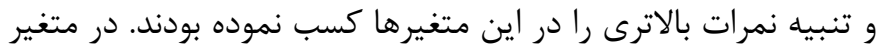

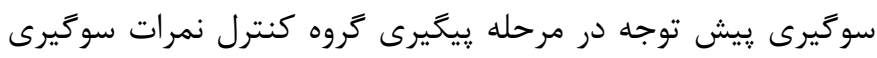

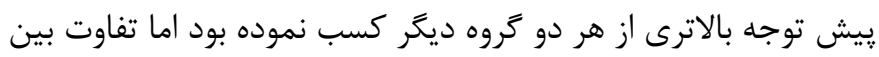

جدول r. آزمون تعقيبى بون فرونى براى سه متغير سوكيرى توجه، بيش توجه و وسوسه در مرحله پِ آزمون و پييكيرى

\begin{tabular}{|c|c|c|c|c|c|}
\hline $\mathrm{P}$ & خطاى استاندارد & تفاوت ميانكينها (I-J) & تروه (J) & (I) كروه & متغير \\
\hline.. .1 & $91 \cdot \Delta$ & rQ/AF & اصلاح سو كيرى & كنترل & \multirow{3}{*}{ سو يسيري توجه در } \\
\hline $.1 . .1$ & 91.9 & $F \Delta / \Delta T$ & اصلاح با تقويت & كنترل & \\
\hline .1 .94 & $91 \cdot 0$ & $19 / 99$ & اصلاح با تقويت & اصلاح سوَيرى & \\
\hline . & $\Delta / 99$ & $\mid Q / \cdot r$ & اصلاح سوَيرى & كنترل & \multirow{3}{*}{ سوكيرى توجه درى } \\
\hline $.1 . .1$ & $\Delta / 99$ & $r r / 4 V$ & اصلاح با تقويت & كنترل & \\
\hline $.1 . .9$ & $\Delta / 99$ & IN/FF & اصلاح با تقويت & اصلاح سوكيرى & \\
\hline.. .1 & $\Delta / \Delta r$ & $r \cdot 109$ & اصلاح سوكيرى & 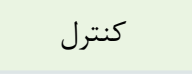 & \multirow{3}{*}{ سو ديرى يِيش توزمون } \\
\hline $.1 . .1$ & $\Delta / \Delta \Lambda$ & re/v. & اصلاح با تقويت & 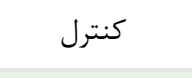 & \\
\hline $.1 \cdot 1$ & $\Delta / 9)$ & 1911. & اصلاح با تقويت & اصلاح سوكيرى & \\
\hline .1 .1 & $\Delta / F$ & $\mid Q / F T$ & اصلاح سوكيرى & كنترل & \multirow{3}{*}{ سو ديرى يِيشيرى توجه } \\
\hline $.1 . .1$ & $\Delta / F \Delta$ & $r \cdot / 4$. & اصلاح با تقويت & كنترل ل & \\
\hline $1 / \cdot \cdot$ & $\Delta / \Psi^{\prime} \Lambda$ & $r / 91$ & اصلاح با تقويت & اصلاح سوكيرى & \\
\hline $.1 \cdot \Delta$ & $1 / 19$ & r/AF & اصلاح سوَيرى & كنترل ل & \multirow{3}{*}{ يس آزمونه در } \\
\hline $.1 . .1$ & $1 / 14$ & $9 / \pi)$ & اصلاح با تقويت & كنترل ل & \\
\hline .1 .1 & $1 / 1 V$ & $r / \& V$ & اصلاح با تقويت & اصلاح سوكيرى & \\
\hline$\cdot 11$ & $1 / \cdot 1$ & T/Tr & اصلاح سوَيرى & كنترل & \multirow{3}{*}{ وسوسه در بييخيرى } \\
\hline.. .1 & $1 / \cdot 9$ & V/VG & اصلاح با تقويت & كنترل & \\
\hline.$/ .1$ & $1 / \cdot 9$ & $\Delta / F q$ & اصلاح با تقويت & اصلاح سوَيرى & \\
\hline
\end{tabular}

براى مثال مشخص شد كه در هر دو مرحله يسآزمون و پيیخيرى از

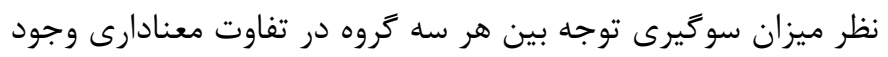

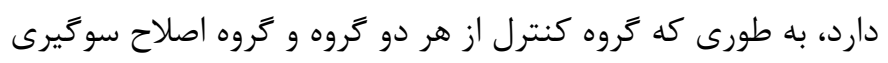

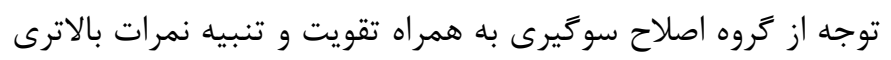

يافتهاى مطالعه حاضر تفاوتهاى معنادارى بين زروههاى مختلف

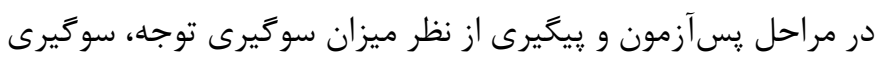
ييش توجه و وسوسه و نسبت به نشانهاى مرتبط با مواد نشان داد. 
اساس، مكانيسم اصلاح سوخيرى توجه بر اساس نظريه دلمشغولى كنونى مىتواند تبيين گردد. يزوهش حاضر اين يافته ارزشمند را حاصل كرد كه گروه اصلاح سوگيرى توجه به همراه تقويت و تنبيه بيش از گروه اصلاح سوگيرى توجه با كاهش سوگيرى توجه مواجه شده است. دليل استفاده از تقويت و تنبيه به همراه مداخله كلاسيك اصلاح سوگيرى توجه اين

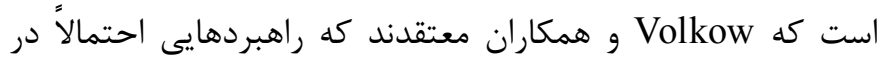
جلوگيرى از لغزش افراد وابسته به مواد سودمند خواهند بود كه بتوانند ارزش §اداشى نشانهاى مرتبط با مواد را كاهش و ارزش ياداشى نشانههاى غير مرتبط با مواد را افزايش دهند و اثر شرطى محركهاى شرطى شده را خنثى نمايند (ع)). همجنين نتايج به دست آمده در پسآزمون تا زمان ڤيگيرى ڤايدار باقى ماند. در غالب مطالعات از پيخيرى جهت بررسى گايدارى نتايج استفاده نشده است. تنها سه مطالعه با پيخيرى استفاده شده است.

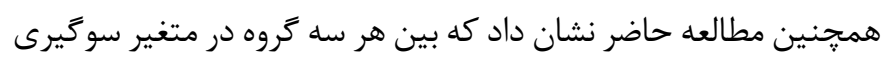
ييش توجه در يسآزمون در يسآزمون تفاوت معنادارى وجود دارد، به طورى كه گروه كنترل از هر دو گروه و گروه اصلاح سوگيرى توجه از گروه اصلاح سوگيرى به همراه تقويت و تنبيه نمرات بالاترى را در اين متغيرها كسب نمودهاند. هرجند، در مرحله يِيگيرى گروه كنترل نمرات سو گيرى ييش توجه بالاترى از هر دو گروه ديخر كسب نموده است، اما تفاوت بين زروه اصلاح سوخيرى توجه با گروه اصلاح سو همراه تقويت و تنبيه معنادار نيست. لزوم بهبود سوگيرى بيش توجه در مطالعاتى آشكار مىشود كه بر اهميت اين نوع سوخيرى به خصوص

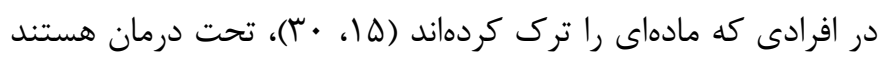

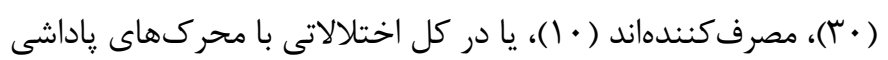
(q) صحه مى گذارند. از اين منظر، ضرورى است كه علاوه بر تمركز بر روى اصلاح سوگيرى توجه، اصلاح سوگيرى ييش توجه را نيز مد نظر قرارداد. اين امر به ويزه در مطالعه حاضر كليدى بود، جرا كه احتمالاً معتادان در حال ترك به مراتب بيش از افراد مصرف كننده از راهبردهاى اجتناب توجه استفاده مى كنند، اما احتمالاً در سوگيرى يِيش توجه مشكلاتى خواهند داشت. يافتههاى مطالعه حاضر مىتواند نويدبخش اين حوزه جديد از يزوهشها باشد. به هر حال، مطالعه حاضر حاكى از اين بود كه اصلاح سوگيرى توجه در معتادان در حال ترك مىتواند بر كاهش وسوسه آنها مؤثر باشد. برخى مطالعات نشان مىدهند كه تمايل به مصرف مواد مىتواند از طريق محركهاى مرتبط با مواد فعال شود (TF) و اين كه سوگيرى توجه، مؤلفه شناختى وسوسه است و يا اين كه مسئول آن مىباشد،
را در اين متغير كسب نمودهاند. اين نتيجه همخوان با برخى مطالعات

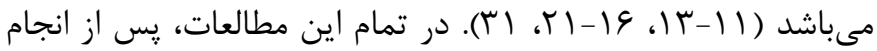
مداخله اصلاح سوگيرى توجه، ميزان سوگيرى توجه نسبت به گروه كنترل كاهش يافته است. يكى از مطالعاتى كه نتيجهاى ناهمخوان با يزوهش حاضر دارد، توسط McHugh و همكاران انجام شده است. در اين مطالعه، برخلاف آنجه پيشبينى مىشد تفاوتى بين دو گروه در ميزان سو گيرى توجه يس از يك مداخله يك جلسهاى به دست مست نيامد. اين يزوهشگران نتيجه گرفتند كه احتمالاً يك مداخله تك جلسهاى براى ايجاد تغييرات معنادار ناكافى است (•F). همجنين مطالعه ديگرى نيز اين نتيجه گيرى را تأييد مى كند و معتقدند كه همانطور كه بسيارى از مداخلات درمانى در يك جلسه رخ نمى دهند، ممكن است اصلاح سوگيرى توجه نيز از اين قاعده مستثنا نباشد و بايد مداخلات جند جلسهاى را به نظاره نشست (TY). شاهد ديخر اين ادعا، مطالعه Lopes و همكاران است كه در آن ول و فرد سيكارى در سه ₹روه به مدت دو هفته تحت سه شرايط قرار گرفتند: گروه اجتناب ץ جلسهاى (ץ جلسه مداخله اجتناب توجه دريافت كردند)، گروه اجتناب يك جلسهاى (يك جلسه مداخله اجتناب در هفته اول و دو جلسه مداخله كنترل يا يلاسيبو دريافت كردند) و گروه كنترل (r) جلسه مداخله يلاسيبو دريافت كردند). در سنجش مجدد يس از

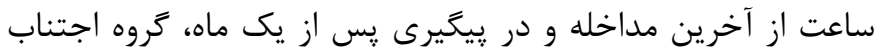
سه جلسهاى تفاوت معنادار زيادى در ميزان سوگيرى توجه نسبت به دو گروه ديخر ييدا كرد و گروه كنترل و اجتناب يك جلسهاى تفاوتى با هم نداشتند (Tr). اين نكته حائز اهميت است كه در مطالعه حاضر از مداخله دو جلسهاى اصلاح سوگيرى توجه استفاده گرديد. يكى از تبيينها براى اثربخشى مداخله اصلاح سوگيرى توجه توسط نظريه دلمشغولى كنونى (Current Concerns Theory) فراهم مى آيد. بر اساس اين نظريه، مغز افراد مصرفكننده در يیى ييدا كردن مواد بوده و به همين دليل توجه آنها سوگيرانه است. مداخله اصلاح سو گيرى توجه در بافت اين نظريه مىتواند دلمشغولى جديد را براى

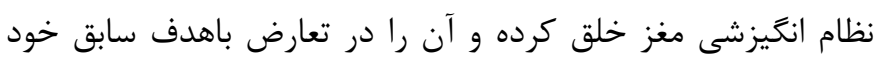
قرار دهد. اين امر منجر به تضعيف جذابيت محركهاى مرتبط با مواد مىتواند شود (Yl). همجنين در مطالعه حاضر از معتادان در حال

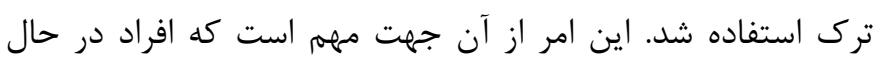
ترك احتمالاً براى مصرف مواد انخيزهاى ندارند، بلكه بالعكس براى إن اجتناب از مصرف مواد انگيزه دارند. اين امر مىتواند به بهبود بيشتر سوگيرى توجه نسبت به نشانههاى مواد با توجه به قدرت بيشتر سيستم انخيزشى تشخيص صحيح جهت ريكان منجر شود. بر اين 


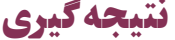

به هر حال، مطالعه حاضر حاكى از اين بود كه اصلاح سوگيرى توجه در معتادان در حال ترك مىتواند بر كاهش وسوسه آنها مؤثر باشد. به آنه نظر مىرسد كه يزوهش حاضر اين يافته ارزشمند را حاصل كرد كه كروه اصلاح سو كيرى توجه به همراه تقويت و تنبيه بيش از كروه اصلاح سوكيرى توجه با كاهش سوكيرى توجه مواجه شده است. افزودن تقويت و تنبيه به مداخله كلاسيك اصلاح سوكيرى توجه مىتواند به به لونه بهبود اثربخشى اين مداخله بيانجامد. همجنين مداخلات مبتنى بر اصلاح سوكيرى توجه، مداخلهاى كار آمد هستند.

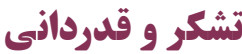

نويسندكان مقاله مراتب سياس و قدردانى خود را ار مراكز درمانى ترك اعتياد شهرستان اهواز، افر اد نمونه و همهُ دست اندر كاران اداره كل محترم بهزيستى شهرستان اهواز كه در انجام اين يزوهش ما را يارى فرمودند،

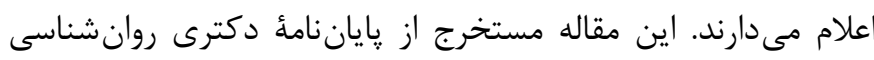

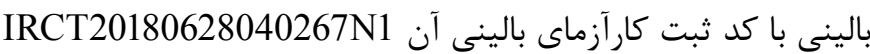

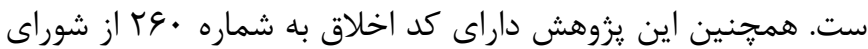
يزوهشى دانشكده علوم تربيتى و روانشناسى دانشكاه شهيد جمران

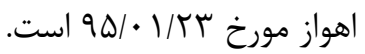

\section{References}

1. Salehi Fadardi J, Ziaei SS. Implicit cognitive processes and attention bias toward addictive behaviors: Introduction, development and application of addiction stroop test. Journal of Fundamentals of Mental Health. 2010;12(1):358-389. (Persian)

2. Kamali A. Meta-analysis of comparing personal and environmental factors effective in addiction relapse (Iran, 20042012). Research on Addiction. 2014;8(30):35-52. (Persian)

3. Goli S, Emamipour S, Javanmard G. The effects of teaching living skills on reduction of bias attention to the tempting stimuli related to drugs in people who have quit them. Research on Addiction. 2010;4(14):31-42. (Persian)

4. Sarrami H, Ghorbami M, Taghavi M. The survey two decades of prevalence studies among Iran university students. Research on Addiction. 2013;7(27):9-36. (Persian)

5. Taremian F, Bolhari J, Peyravi H, Asgari A. Drug use prev-
با توجه به اين امر، اصلاح سوگيرى توجه مىتواند منجر به كاهش وسوسه مصرف مواد شود (Y). از آنجا كه در مداخله اصلاح سوكيرى توجه، ميزان توجه به محركهاى مرتبط با مواد كاهش مى يابد، در

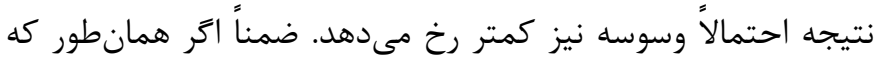

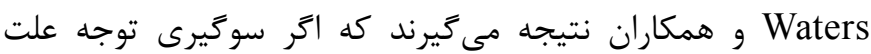

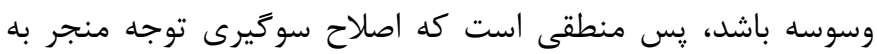

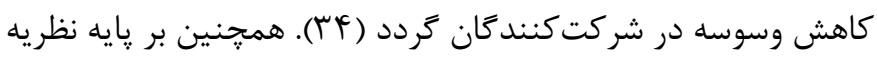
دلمشغولى كنونى نيز مىتوان اذعان نمود كه جون سيستم انگَيزشى مصرف مواد در افراد طى مداخله اصلاح سوگيرى توجه در تقابل با سيستم انخيزشى ڤاسخ صحيح به جهت پيكان قرار مى گيرد، بار انخيزشى خود را تا حدى از دست مىدهد و در نتيجه نمىتواند يك ليك دلمشغولى برجسته در نظام انكيزشى فرد باشد كه در واقع منجر به كاهش وسوسه مىشود (YV). يزوهش حاضر از آن جهت كه تنها بر روى نمونه مردان و تنها در شهر اهواز و به صورت نمونهَيرى

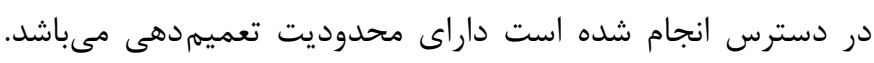

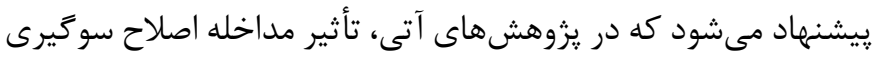

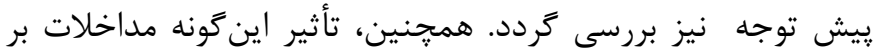
تعميم ابزارى، تعميم محركى، براى مثال (Tr) و ميزان مصرف يا تيان لغزش نيز بررسى كردد.

alence among students of universities of medical sciences in Tehran. Research on Addiction. 2014;7(28):9-21. (Persian)

6. Alaee R, Kadivar P, Mohammadkhani S, Sarami G, Alaee S. The prevalence of tobacco, hubble-bubble, alcoholic drinks, drugs, and stimulants among high-school students. Research on Addiction. 2011;5(18):99-114.

7. Yaghubi H, Taremian F, Peyravi H, Zafar M. Drug use prevalence among college students of ministry of sceince, research and technology, Iran (2012). Research on Addiction. 2015;8(32):9-36. (Persian)

8. Ornstein T, Iddon J, Baldacchino A, Sahakian B, London M, Everitt B, et al. Profiles of cognitive dysfunction in chronic amphetamine and heroin abusers. Neuropsychopharmacology. 2000;23(2):113-126.

9. Ryan F. Attentional bias and alcohol dependence: A con- 
trolled study using the modified Stroopparadigm. Addictive Behaviors. 2002;27(4):471-482.

10. Nejati V, Sadeghi Meresht A, Moradi Y, Barzegar B. The influence of consciousness on inhibition of and attentional bias to stimuli associated with drugs among heroin users. Research on Addiction. 2014;8(30):21-34. (Persian)

11. Fadardi JS, Cox WM. Reversing the sequence: Reducing alcohol consumption by overcoming alcohol attentional bias. Drug and Alcohol Dependence. 2009;101(3):137-145.

12. Field M, Duka T, Eastwood B, Child R, Santarcangelo M, Gayton M. Experimental manipulation of attentional biases in heavy drinkers: Do the effects generalise?. Psychopharmacology. 2007;192(4):593-608.

13. Field M, Eastwood B. Experimental manipulation of attentional bias increases the motivation to drink alcohol. Psychopharmacology. 2005;183(3):350-357.

14. Flaudias V, Brousse G, de Chazeron I, Planche F, Brun J, Llorca P-M. Treatment in hospital for alcohol-dependent patients decreases attentional bias. Neuropsychiatric Disease and Treatment. 2013;9:773-779.

15. Noel X, Colmant M, Van Der Linden M, Bechara A, Bullens Q, Hanak C, et al. Time course of attention for alcohol cues in abstinent alcoholic patients: The role of initial orienting. Alcoholism: Clinical and Experimental Research. 2006;30(11):1871-1877.

16. Schoenmakers T, Wiers RW, Jones BT, Bruce G, Jansen A. Attentionalre-training decreases attentional bias in heavy drinkers without generalization. Addiction. 2007;102(3):399405.

17. Schoenmakers TM, De Bruin M, Lux IF, Goertz AG, Van Kerkhof DH, Wiers RW. Clinical effectiveness of attentional bias modification training in abstinent alcoholic patients. Drug and Alcohol Dependence. 2010;109(1-3):30-36.

18. Attwood AS, O’Sullivan H, Leonards U, Mackintosh B, Munafo MR. Attentional bias training and cue reactivity in cigarette smokers. Addiction. 2008;103(11):1875-1882.

19. Field M, Duka T, Tyler E, Schoenmakers T. Attentional bias modification in tobacco smokers. Nicotine \& Tobacco Research. 2009;11(7):812-822.

20. Kerst WF, Waters AJ. Attentional retraining administered in the field reduces smokers' attentional bias and craving. Health Psychology. 2014;33(10):1232-1240.

21. Nowrouzi A, Taghavi M. Smokers attentional bias modification: Effect of operant conditioning. Journal of Clinical Psychology. 2014;6(3):43-53. (Persian)

22. Nowrouzi A, Taghavi M, Mohammadi N. Pre-attentional bias modification in smokers: Generalization to a new stimulus and task paradigm. Advances in Cognitive Sciences. 2015;17(1):25-34. (Persian)

23. Lopes FM, Pires AV, Bizarro L. Attentional bias modification in smokers trying to quit: A longitudinal study about the effects of number of sessions. Journal of Substance Abuse Treatment. 2014;47(1):50-57.

24. Enayat J, Javanmard G, Mammagani J. The comparison of attention biases to opiates in substance dependent and treated clients of therapeutic clinics and narcotics anonymous memberships. Research on Addiction. 2012;6(23):27-37. (Persian) 25. Marks KR. Examining the behavioral mechanism of cocaine cue attentional bias [PhD Dissertation]. Kentucky:University of Kentucky;2015.

26. Cousijn J, Watson P, Koenders L, Vingerhoets WAM, Goudriaan AE, Wiers RW. Cannabis dependence, cognitive controland attentional bias for cannabis words. Addictive Behaviors. 2013;38(12):2825-2832.

27. Zamani SN, Mansouri H, Fazilatpour M, Shamsai Z. A comparison of attentional bias towards drug cues in addicts and non-addicts. International Journal of High Risk Behaviors \& Addiction. 2014;3(3):e18669.

28. Robinson TE, Berridge KC. Incentive-sensitization and addiction. Addiction. 2001;96(1):103-114.

29. Theeuwes J. Irrelevant singletons capture attention. In: Itti L, Rees G, Tsotsos JK, editors. Neurobiology of attention. Burlington:Academic Press;2005. pp. 418-424.

30. Stormark KM, Field NP, Hugdahl K, Horowitz M. Selec- 
tive processing of visual alcohol cues in abstinent alcoholics: An approach-avoidance conflict?. Addictive Behaviors. 1997;22(4):509-519.

31. McGeary JE, Meadows SP, Amir N, Gibb BE. Computer-delivered, home-based, attentional retraining reduces drinking behavior in heavy drinkers. Psychology of Addictive Behaviors. 2014;28(2):559-562.

32. Cox WM, Fadardi JS, Intriligator JM, Klinger E. Attentional bias modification for addictive behaviors: clinical implications. CNS Spectrums. 2014;19(3):215-224.

33. Wiers RW, Cox WM, Field M, Fadardi JS, Palfai TP, Schoenmakers T, et al. The search for new ways to change implicit alcohol-related cognitions in heavy drinkers. Alcoholism: Clinical and Experimental Research. 2006;30(2):320-331.

34. Waters AJ, Marhe R, Franken IH. Attentional bias to drug cues is elevated before and during temptations to use heroin and cocaine. Psychopharmacology. 2012;219(3):909-921.

35. Anderson BA, Laurent PA, Yantis S. Value-driven attentional capture. Proceedings of the National Academy of Sciences. 2011;108(25):10367-10371.
36. Volkow ND, Fowler JS, Wang GJ, Goldstein RZ. Role of dopamine, the frontal cortex and memory circuits in drug addiction: Insight from imaging studies. Neurobiology of Learning and Memory. 2002;78(3):610-624.

37. Sarmad Z, Bazargan A, Hejazi A. Research Methods in Behavioral Sciences. Tehran:Agah Publishing;2019. (Persian)

38. Nowrouzi A, Taghavi SMR, Mohammadi N. Pre-attentional bias modification in smokers: generalization to a new stimulus and task paradigm. Advances in Cognitive Sciences. 2015;17(1):25-34. (Persian)

39. Somoza E, Baker S, Himmler C, LoCastro J, Mezinskis J, Simon S, et al. The brief substance craving scale-measuring craving in clinical trials. Problems of Drug Dependence: Proceedings of the 61st Annual Scientific Meeting, the College on Problems of Drug Dependence, Inc. Nida Research Monograph. 1999;180:304-306.

40. McHugh RK, Murray HW, Hearon BA, Calkins AW, Otto MW. Attentional bias and craving in smokers: The impact of a single attentional training session. Nicotine \& Tobacco Research . 2010;12(12):1261-1264. 